\title{
Ammonia-oxidizing archaea possess a wide range of cellular ammonia affinities
}

\author{
Man-Young Jung iD $^{1,2,3,14 \bowtie}$, Christopher J. Sedlacek (iD ${ }^{1,4,14 凶}$, K. Dimitri Kits ${ }^{1}$, Anna J. Mueller (iD ${ }^{1}$, Sung-Keun Rhee (iD ${ }^{5}$, Linda Hink ${ }^{6,12}$, \\ Graeme W. Nicol (D) ${ }^{6}$, Barbara Bayer ${ }^{1,7,13}$, Laura Lehtovirta-Morley $\mathbb{D i D}^{8}$, Chloe Wright ${ }^{8}$, Jose R. de la Torre (iD) ${ }^{9}$, Craig W. Herbold ${ }^{1}$, \\ Petra Pjevac (iD ${ }^{1,10}$, Holger Daims (iD) ${ }^{1,4}$ and Michael Wagner (iD) ${ }^{1,4,11}$
}

(c) The Author(s) 2021

Nitrification, the oxidation of ammonia to nitrate, is an essential process in the biogeochemical nitrogen cycle. The first step of nitrification, ammonia oxidation, is performed by three, often co-occurring guilds of chemolithoautotrophs: ammonia-oxidizing bacteria ( $A O B)$, archaea (AOA), and complete ammonia oxidizers (comammox). Substrate kinetics are considered to be a major niche-differentiating factor between these guilds, but few AOA strains have been kinetically characterized. Here, the ammonia oxidation kinetic properties of 12 AOA representing all major cultivated phylogenetic lineages were determined using microrespirometry. Members of the genus Nitrosocosmicus have the lowest affinity for both ammonia and total ammonium of any characterized AOA, and these values are similar to previously determined ammonia and total ammonium affinities of AOB. This contrasts previous assumptions that all AOA possess much higher substrate affinities than their comammox or AOB counterparts. The substrate affinity of ammonia oxidizers correlated with their cell surface area to volume ratios. In addition, kinetic measurements across a range of $\mathrm{pH}$ values supports the hypothesis that-like for $\mathrm{AOB}$-ammonia and not ammonium is the substrate for the ammonia monooxygenase enzyme of AOA and comammox. Together, these data will facilitate predictions and interpretation of ammonia oxidizer community structures and provide a robust basis for establishing testable hypotheses on competition between $\mathrm{AOB}, \mathrm{AOA}$, and comammox.

The ISME Journal (2022) 16:272-283; https://doi.org/10.1038/s41396-021-01064-z

\section{INTRODUCTION}

Nitrification, the microbially mediated oxidation of ammonia $\left(\mathrm{NH}_{3}\right)$ to nitrate $\left(\mathrm{NO}_{3}{ }^{-}\right)$via nitrite $\left(\mathrm{NO}_{2}{ }^{-}\right)$, is a key process of the biogeochemical nitrogen cycle [1, 2] and is mostly driven by autotrophic microorganisms that are capable of growing with $\mathrm{NH}_{3}$ and/or $\mathrm{NO}_{2}{ }^{-}$as sole energy generating substrates. For more than a century, ammonia-oxidizing bacteria (AOB) were considered the lone drivers of aerobic ammonia oxidation by autotrophs, as ammonia-oxidizing archaea (AOA) $[3,4]$ and complete ammonia oxidizers (comammox) [5-7] eluded discovery until relatively recently. Our present-day understanding of ammonia oxidation is quite different: $A O A$ frequently outnumber $A O B$ in oligotrophic habitats [8-10], while AOB often dominate in eutrophic environments [11-14]. Comammox have been shown to be abundant and sometimes even dominant in various natural and engineered environments [15-19], although the habitat range and ecophysiology of comammox remains less well resolved. Notably, in the majority of ecosystems-with the exception of the marine environment, where no comammox has been detected-AOA, $\mathrm{AOB}$, and comammox often co-occur.

Many environmental and physiological factors are known to affect the niche differentiation and habitat selection of ammoniaoxidizing microorganisms (AOM) [20, 21]. In fact, AOM species display differential responses to factors such as $\mathrm{pH}$, oxygen concentrations, light conditions, temperature, metal and organic compounds, and substrate concentrations [22-27]. These differential responses are frequently used to explain the co-occurence of $\mathrm{AOM}$ across environments. However, the cellular properties underlying these niche-differentiating physiological characterstics of AOM often remain unclear.

The substrate affinity of a microorganism can be expressed with Michaelis-Menten kinetic equations, analogous to enzyme kinetics, defined by an apparent-half-saturation concentration (substrate affinity; $\left.K_{\mathrm{m}(\mathrm{app})}\right)$ and a maximal reaction rate $\left(V_{\text {max }}\right)$. In addition, the specific substrate affinity $\left(a^{\circ} ; V_{\max }\right.$ divided by $\left.K_{\mathrm{m}(\mathrm{app})}\right)$ takes into account both the cellular $K_{\mathrm{m}(\mathrm{app})}$ and $V_{\text {max }}$ and is thus

\footnotetext{
${ }^{1}$ Department of Microbiology and Ecosystem Science, Centre for Microbiology and Environmental Systems Science, University of Vienna, Vienna, Austria. ${ }^{2}$ Department of Biology

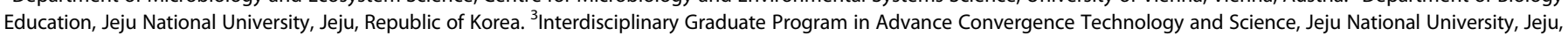

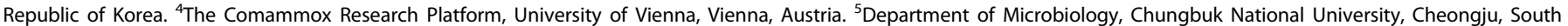

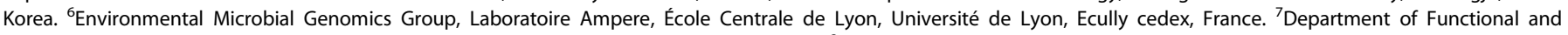

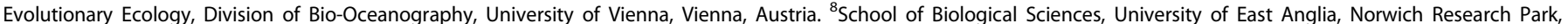

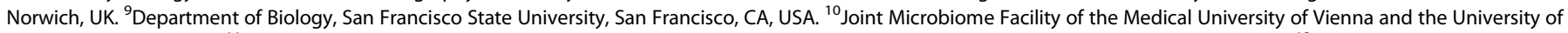

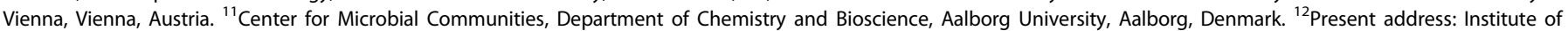

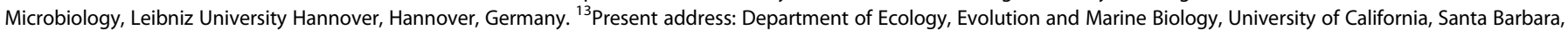
CA, USA. ${ }^{14}$ These authors contributed equally: Man-Young Jung, Christopher J. Sedlacek. ${ }^{凶}$ email: myjung@jejunu.ac.kr; sedlacekc88@univie.ac.at
} 
an appropriate measure for comparing interspecies competitiveness [28]. Throughout this study, instantaneous substratedependent kinetic properties were measured which represent cellular activity in the absence of growth. Therefore, the Michaelis-Menten modeled kinetic properties discussed here $\left(K_{\mathrm{m}(\mathrm{app})}\right.$ and $\left.V_{\mathrm{max}}\right)$ differ from Monod modeled kinetic properties $\left(K_{\mathrm{s}}\right.$ and $\left.\mu_{\max }\right)$, which also take into account other cellular process (e.g., growth, division, stress, and repair). Our focus on Michaelis-Menten modeled kinetic properties is in part due to the enormous challenges that would be associated with growing such a wide array of AOA under the continuous cultivation conditions necessary to determine Monod kinetic properties.

Based on whole cell kinetic properties, AOM were observed to have different survival or lifestyle strategies. The first study investigating the whole cell kinetics of an AOA revealed that Nitrosopumilus maritimus SCM1 displayed a low maximum $\mathrm{NH}_{3}$ oxidation rate $\left(V_{\text {max }}\right)$, but a very high substrate affinity and $a^{\circ}$ for $\mathrm{NH}_{3}$, compared with AOB [29]. Based on these findings with a single $A O A$ strain, substrate affinity was postulated as a major niche-differentiating factor between $A O A$ and $A O B[20,29]$. However, recently it was shown that (i) the only comammox isolate Nitrospira inopinata has a $K_{\mathrm{m}(\mathrm{app})}$ for $\mathrm{NH}_{3}$ lower than that of all characterized $A O B$ and (ii) that the $K_{m(a p p)}$ for $\mathrm{NH}_{3}$ in a few nonmarine $A O A$ strains is not always orders of magnitude lower than that of $A O B$ [5]. Nevertheless, the AOA with comparatively high $K_{\mathrm{m}}$ (app) for $\mathrm{NH}_{3}$ (low affinity) still possess a significantly higher $a^{\circ}$ than $A O B$, indicating that these $A O A$ are still more efficient substrate scavengers [5]. Furthermore, temperature and $\mathrm{pH}$, which are known niche-differentiating factors [30-32], have previously been shown to affect the substrate affinity of $A O B$ [33-35], but the influence of these parameters on the substrate affinity of AOA and comammox remains to be determined.

In this study, the whole cell kinetic properties of 12 AOA species were determined through instantaneous substrate-dependent microrespirometry (MR) experiments. These include representatives from all four major AOA phylogenetic lineages, isolated or enriched from various habitats (i.e., marine, terrestrial, and geothermal) and possessing a wide variety of $\mathrm{pH}$ and temperature growth optima. In these analyses, we also explored the links between the cellular $K_{\mathrm{m}(\mathrm{app})}$ and $a^{\circ}$ of AOM with their cell surface area to volume $(\mathrm{SA} / \mathrm{V})$ ratio. Furthermore, by performing MR experiments at different $\mathrm{pH}$ values we investigated whether the undissociated $\mathrm{NH}_{3}$ or ammonium $\left(\mathrm{NH}_{4}{ }^{+}\right)$is the substrate for $\mathrm{AOA}$ and comammox.

\section{MATERIALS AND METHODS}

\section{Cultivation of ammonia oxidizers}

Several previously described growth media were used to cultivate the AOM used in this study. A comprehensive guide with medium components and cultivation conditions is provided in the Supplementary Materials and Methods, Tables S1, and S2. Briefly, all cultures were grown without shaking, in the dark, at their optimum growth temperature and $\mathrm{pH}$, unless otherwise stated. Ammonium $\left(\mathrm{NH}_{4} \mathrm{Cl}\right)$ from pre-sterilized stocks was added as substrate as needed. The growth medium of Nitrosarchaeum koreense MY1, 'C $a$. Nitrosotenuis chungbukensis' MY2, 'C $a$. Nitrosotenuis uzonensis' N4, N. maritimus SCM1, Nitrosopumilus piranensis D3C, and Nitrosopumilus adriaticus NF5 was supplemented with sodium pyruvate $(0.5 \mathrm{mM})$ at all times. The $\mathrm{pH}$ of all growth media were adjusted when necessary by addition of sterile $\mathrm{NaHCO}_{3}$. Ammonia oxidation activity was determined by measuring ammonium, nitrite, and nitrate concentrations photometrically [36-39] using an Infinite 200 Pro M Nano+ spectrophotometer (Tecan Group AG, Switzerland).

\section{Novel AOA enrichments and pure culture}

The sampling site, enrichment process, and initial strain characterization details for the two novel thermophilic AOA enrichment cultures ' $\mathrm{C} a$. Nitrosofervidus tenchongensis' DRC1, and ' $C a$. Nitrososphaera nevadensis' GerE used in this study are provided in the Supplementary Materials and
Methods. In addition, in this study, 'Ca. N. uzonensis' N4 was isolated as a pure culture from a previously described geothermal spring enrichment culture [40]. Further details are provided below and in the Supplementary Materials and Methods.

\section{Phylogenetic analysis}

Taxa chosen for phylogenetic reconstruction met at least one of three different criteria: (1) inclusion in the current study, (2) published as a culture/enrichment or (3) designation as a "GTDB representative of species" for the group of taxa classified as "Nitrososphaerales" by the Genome Taxonomy Database release 05-RS95 [41]. A concatenated alignment of 34 universal genes (43 markers) was automatically constructed using CheckM [42]. IQ-TREE v 2.1.2 [43] was used for phylogenetic reconstruction following automatic model determination with modelFinder [44], which identified $L G+F+R 6$ as the best-fit model according to the Bayesian Information Criterion (BIC). Bipartition support was determined with ultrafast bootstraps (UFboots [45]).

\section{Substrate-dependent oxygen uptake measurements}

Cellular substrate oxidation kinetics were determined from instantaneous substrate-dependent oxygen uptake measurements as previously described $[5,29,46]$. Briefly, measurements were performed with a MR system, equipped with a PA 2000 picoammeter and a $500 \mu \mathrm{m}$ tip diameter OX-MR oxygen microsensor (Unisense, Denmark), polarized continuously for at least $24 \mathrm{~h}$ before use.

Active AOA, AOB, and $N$. inopinata cells were harvested $(4000 \times g$, $10 \mathrm{~min}, 20^{\circ} \mathrm{C}$ ) from ammonium replete active cultures, using $10 \mathrm{kDa}$-cutoff, Amicon Ultra-15 centrifugal filter units (Merck Millipore, Germany). Concentrated cells were washed with and resuspended in substrate-free medium appropriate for the respective cultures. Exceptions were ' $\mathrm{Ca}$. Nitrosocosmicus franklandus' $\mathrm{C} 13$ and the marine AOA, N. maritimus SCM1, $N$. piranensis D3C, and N. adriaticus NF5. These four AOA strains were not active in the MR chambers after attempts to concentrate their biomass. Therefore, ammonium concentrations were monitored daily for these four cultures, and cells were used without concentration for MR promptly upon substrate depletion [29]. AOM harvested cells for MR experiments were incubated for at least $30 \mathrm{~min}$ in a recirculating water bath set to the experimental temperature (Tables S2 and S3) prior to being transferred to the MR chambers $(\sim 2 \mathrm{ml})$.

In addition to MR experiments at optimal growth temperature and $\mathrm{pH}$ (Table S2), MR experiments were also performed at non-optimal growth temperatures and medium pH (Table S3). 'Ca. N. oleophilus' MY3 was cultivated at $30^{\circ} \mathrm{C}$, harvested with centrifugal filter units (see above), and incubated for $\sim 2 \mathrm{~h}$ in substrate-free medium across a range of temperatures $\left(25,30\right.$, and $\left.35^{\circ} \mathrm{C}\right)$. MR experiments were then performed at the respective preincubation temperature. Likewise, $N$. inopinata and 'Ca. N. oleophilus' MY3 cells were harvested with centrifugal filter units (see above) and resuspended in substrate-free medium containing $10 \mathrm{mM}$ HEPES (pH 7.4). The $\mathrm{pH}$ was adjusted to $6.5-8.4$ with $1 \mathrm{M} \mathrm{HCl}$ or $1 \mathrm{M} \mathrm{NaOH}$ (Table S3). These cultures were then incubated at their optimum growth temperature for $\sim 1 \mathrm{~h}$ prior to cellular kinetic measurements. Culture $\mathrm{pH}$ was determined before and after oxygen uptake measurements to confirm the $\mathrm{pH}$ did not change during MR. Substrate-dependent oxygen uptake measurements were performed as described below.

For all MR experiments, glass MR chambers containing glass-coated magnetic stir bars were filled headspace-free, sealed with MR injection lids, and submerged in a recirculating water bath. An OX-MR microsensor was inserted into each MR chamber and left to equilibrate (300 rpm, $\sim 1 \mathrm{~h}$ ). Exact temperatures used for each culture and experiment are provided in Tables S2 and S3. Stable background sensor signal drift was measured for at least $15 \mathrm{~min}$ prior to initial substrate injections, and the background oxygen consumption rate was subtracted from the measured oxygen uptake rates. Hamilton syringes ( 10 or $50 \mu l$; Hamilton, USA) were used to inject $\mathrm{NH}_{4} \mathrm{Cl}$ stock solutions into MR chambers. Both single and multiple trace oxygen uptake measurements were performed. For single trace measurements, a single substrate injection was performed, and oxygen uptake was recorded until substrate depletion. For multiple trace measurements, multiple injections of varying substrate concentration were performed in a single MR chamber. Once stable, discrete slopes of oxygen uptake were calculated following each substrate injection. Immediately following oxygen uptake measurements, the total ammonium concentration and $\mathrm{pH}$ of the MR chamber contents were determined. The cells were stored at $-20^{\circ} \mathrm{C}$ for protein analysis. Cells were lysed with the Bacterial Protein Extraction Reagent (BPER, Thermo Scientific) and the total 
protein content was determined photometrically with the Pierce bicinchoninic acid Protein Assay Kit (Thermo Scientific) as per the manufacturer's instructions. Before and after MR assays of $N$. piranensis D3C, ' $\mathrm{C} a$. N. uzonensis' N4, and ' $\mathrm{C} a$. N. oleophilus' MY3, an aliquot of culture was filtered onto membranes $(0.2 \mu \mathrm{m}$ polycarbonate GTTP membranes; Merck Milipore, Germany) and DAPI (4',6-diamidino-2-phenylindole; $10 \mu \mathrm{g}$ $\mathrm{ml}^{-1} ; 5 \mathrm{~min}$; room temperature) stained prior to microscopic measurement of biomass cell aggregate size, as described previously [47, 48].

\section{Calculation of kinetic properties}

$K_{\mathrm{m}(\mathrm{app})}$ and $V_{\max }$ were calculated from both single and multiple trace substrate-dependent oxygen uptake measurements. Total ammonium $\left(\mathrm{NH}_{3}+\mathrm{NH}_{4}{ }^{+}\right)$oxidation rates were calculated from oxygen uptake measurements using a substrate to oxygen consumption ratio of 1:1.5 $[5,29]$. Total ammonium uptake rates were fitted to a Michaelis-Menten model using the equation:

$V=\left(V_{\max } \times[S]\right) \times\left(K_{\mathrm{m}(\mathrm{app})}+[S]\right)^{-1}$

where $V$ is the reaction rate $\left(\mu \mathrm{M} \mathrm{h}^{-1}\right), V_{\max }$ is the maximum reaction rate $\left(\mu \mathrm{M} \mathrm{h}^{-1}\right), S$ is the total ammonium concentration $(\mu \mathrm{M})$, and $K_{\mathrm{m}(\mathrm{app})}$ is the reaction half saturation concentration $(\mu \mathrm{M})$. A nonlinear least squares regression analysis was used to estimate $K_{\mathrm{m} \text { (app) }}$ and $V_{\max }$ [49]. The $K_{\mathrm{m} \text { (app) }}$ for $\mathrm{NH}_{3}$ for each strain was calculated based on the $K_{\mathrm{m} \text { (app) }}$ for total ammonium, incubation temperature, $\mathrm{pH}$, and salinity [50]. $K_{\mathrm{m}(\mathrm{app})}$ values for AOM not determined in this study were compiled from the literature $[5,29,33,34,51-55]$. If only total ammonium information was given by the authors for $K_{\mathrm{m}(\mathrm{app})}$, the corresponding $\mathrm{NH}_{3}$ values were calculated based on the reported experimental temperature, $\mathrm{pH}$, and salinity values. $V_{\max }$ values of pure cultures were normalized to culture protein content. The specific substrate affinity $\left(a^{\circ} ; \mathrm{lg}\right.$ wet cells $\left.\mathrm{s}^{-1} \mathrm{~h}^{-1}\right)$ of each pure culture strain was calculated using the equation:

$a^{o}=\left(\frac{V_{\max }}{\text { cellular protein } \times 5.7}\right) \times K_{\mathrm{m}(\mathrm{app})^{-1}}$

Where the $V_{\max }$ is normalized to the protein concentration $\left(\mathrm{g} \mathrm{I}^{-1}\right)$ of the culture in the MR chamber and the factor of $5.7 \mathrm{~g}$ wet cell weight per $\mathrm{g}$ of protein was used for all AOM $[5,29,56]$. The $a^{\circ}$ for $\mathrm{NH}_{3}$ or total ammonium were calculated using the respective $K_{\mathrm{m}(\mathrm{app})}$ for $\mathrm{NH}_{3}$ or total ammonium.

\section{Cell surface area to volume ratio calculation}

Approximate cell SA/V ratios were determined using cell dimensions provided by or calculated from previously published phase contrast, transmission electron, or scanning electron microscopy images (Table S4). The following equations for the surface (SA) area and volume (V) of a sphere (3) and rod (4) were used:

$\mathrm{SA}=4 \pi r^{2} ; \mathrm{V}=4 / 3 \pi r^{3}$

$\mathrm{SA}=2 \pi \mathrm{r}(\mathrm{h}+\mathrm{r}) ; \mathrm{V}=\pi \mathrm{r}^{2} \mathrm{~h}$

where $r$ is the cell radius $(\mu \mathrm{m})$ and $\mathrm{h}$ is the cell length $(\mu \mathrm{m})$. The cell size and volume from published phase contrast images were verified using MicrobeTracker [57].

\section{RESULTS AND DISCUSSION AOA kinetic properties}

In this study we investigated the kinetic properties of 12 AOA strains, including representatives from all four described AOA phylogenetic lineages: Nitrosopumilales (Group I.1a), 'Ca. Nitrosotaleales' (Group I.1a-associated), Nitrososphaerales (Group I.1b), and 'Ca. Nitrosocaldales' (thermophilic AOA clade) [58, 59] (Fig. 1). These $A O A$ isolates and enrichments were obtained from a variety of habitats (marine, soil, sediment, hot spring) and have optimal growth $\mathrm{pH}$ and temperatures ranging from $5.3-7.8$ to $25-72{ }^{\circ} \mathrm{C}$, respectively (Table $\mathrm{S} 2$ ). The substrate-dependent oxygen consumption rates for all AOA tested followed Michaelis-Menten kinetics. Below, the kinetic properties of these AOA are put into a broader context with comparisons to previously characterized AOM. It is important to note that the whole cell kinetic properties, such as substrate competitiveness, detailed here were generated from instantaneous activity measurements in the absence of growth. It is unknown how the substrate competitiveness of nitrifiers may or may not differ from their competitiveness when cellular processes such as growth, division, stress, and repair are involved.

Nitrosopumilales (Group I.1a). From this lineage, three mesophilic marine $(N$. piranensis D3C, $N$. adriaticus NF5, and $N$. maritimus SCM1) $[3,60]$, two agricultural soil ( $N$. koreense MY1 and ' $C a$. $\mathrm{N}$. chungbukensis' MY2) [61,62] and one thermal spring isolate (' $\mathrm{Ca}$. N. uzonensis' N4) [40] were kinetically characterized (Fig. S1). These AOA all displayed a high substrate affinity for $\mathrm{NH}_{3}$, ranging from $\sim 2.2$ to $24.8 \mathrm{nM}$. Thus, all characterized Nitrosopumilales, and not just marine isolates, are adapted to oligotrophic conditions. All possess substrate affinities several orders of magnitude higher (lower $K_{\mathrm{m}(\mathrm{app})}$ ) than any characterized AOB, with the exception of the recently characterized acidophilic gammaproteobacterial $A O B$ 'Ca. Nitrosacidococcus tergens' [55] (Fig. 2a). This finding appears to support the widely reported hypothesis that regardless of the environment, $A O A$ in general are adapted to lower substrate concentrations than $A O B[22,29,30]$. However, as described later, this trend does not apply to all AOA.

As the substrate oxidation kinetics of the marine AOA strain, $N$. maritimus SCM1, originally characterized by Martens-Habbena et al. [29] have recently been disputed [63], they were revisited in this study (Fig. S2). With the same strain of $N$. maritimus used in Hink et al. [63] (directly obtained by the authors), we were able to reproduce (Figs. S1 and S2) the original kinetic properties of $N$. maritimus SCM1 reported in Martens-Habbena et al. [29] ruling out strain domestication during lab propagation as cause for the observed discrepancy. Therefore, the reported differences in the literature possibly reflect the measurements of two distinct cellular properties, $K_{\mathrm{m}(\mathrm{app})}$ [29] and $K_{\mathrm{s}}$ [63], representing the half saturation of activity and growth, respectively. In addition, differences in pre-measurement cultivation and growth conditions could also contribute to these unexpected differences $[63,64]$. More details are provided in the Supplementary Results and Discussion.

'Ca. Nitrosotaleales' (Group I.1a-associated). The only isolated AOA strains in this lineage ' $\mathrm{Ca}$. Nitrosotalea devanaterra' $\mathrm{Nd} 1$ and ' $\mathrm{Ca}$. Nitrosotalea sinensis' $\mathrm{Nd} 2$, are highly adapted for survival in acidic environments and grow optimally at $\mathrm{pH} 5.3[25,65]$. Both display a relatively low affinity for total ammonium $\left(K_{\mathrm{m}(\mathrm{app})}=3.41-11.23\right.$ $\mu \mathrm{M})$, but their affinity for $\mathrm{NH}_{3}$ is among the highest calculated of any AOA characterized $\left(K_{\mathrm{m}(\mathrm{app})}=\sim 0.6-2.8 \mathrm{nM}\right.$ ) (Fig. 2a, $\mathrm{c}$, and Fig. S3). This seemingly drastic difference in substrate affinity for total ammonium versus $\mathrm{NH}_{3}$ is due to the combination of the high acid dissociation constant of ammonium ( $\mathrm{pKa}=9.25)$ and the kinetic properties of these strains being carried out at $\mathrm{pH}$ 5.3. The very limited availability of $\mathrm{NH}_{3}$ under acidic conditions has led to the hypothesis that these acidophilic AOA should be highly adapted to very low $\mathrm{NH}_{3}$ concentrations and possess a high substrate affinity (low $K_{\mathrm{m}(\mathrm{app})}$ ) for $\mathrm{NH}_{3}[66,67]$. Our data corroborate this hypothesis.

Nitrososphaerales (Group I.1b). The AOA strains 'Ca. N. nevadensis' GerE (culture information provided in Supplementary Results and Discussion), ' $\mathrm{Ca}$. N. oleophilus' MY3 [68] and ' $\mathrm{Ca}$. N. franklandus' C13 [69] were kinetically characterized, and contextualized with the previously published kinetic characterization of Nitrososphaera viennensis EN76 and 'Ca. Nitrososphaera gargensis' [5]. Together, the Nitrososphaerales AOA possess a wide range of affinities for $\mathrm{NH}_{3}\left(K_{\mathrm{m} \text { (app) }}=\sim 0.14-31.5 \mu \mathrm{M}\right)$ (Fig. $2 \mathrm{a}$ and Fig. S4). Although this range of $\mathrm{NH}_{3}$ affinities spans more than two orders of magnitude, none of the Nitrososphaerales AOA possess an affinity for $\mathrm{NH}_{3}$ as high as any Nitrosopumilales or ' $\mathrm{C} a$. Nitrosotaleales' AOA (Fig. 2a). 


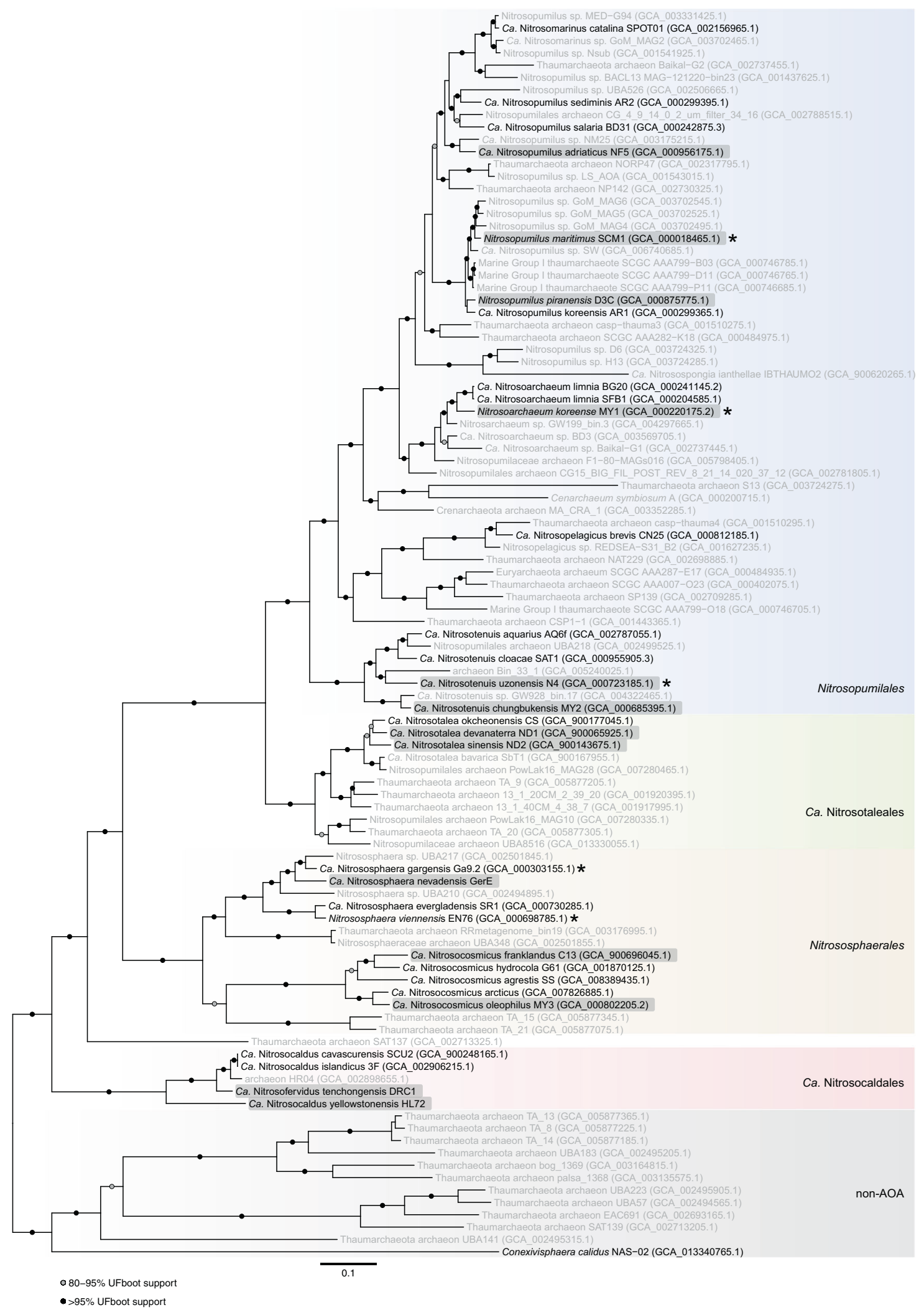

Fig. 1 Phylogenetic reconstruction of ammonia oxidizing archaea (AOA) rooted on closely related non-AOA members of the "Thaumarchaeota". Black taxon labels correspond to AOA from cultures or enrichments. Gray taxon labels correspond to representative metagenome assembled genomes from release 05-RS95 of the genome taxonomy database [41]. AOA that were kinetically characterized in the current study are highlighted in gray and AOA that were previously characterized are indicated with an asterisk $(*)$. The phylogeny was calculated with IQ-TREE under model LG + F + R6 using an alignment of 34 universal genes (43 markers) produced by CheckM [42]. Support values (UFboot) greater than $95 \%$ for bipartitions are shown with a black circle and support values between $80 \%$ and $95 \%$ are shown with a gray circle. Order designations reflect lineages proposed by Alves et al. [59]. The scale bar indicates amino acids changes per site. 

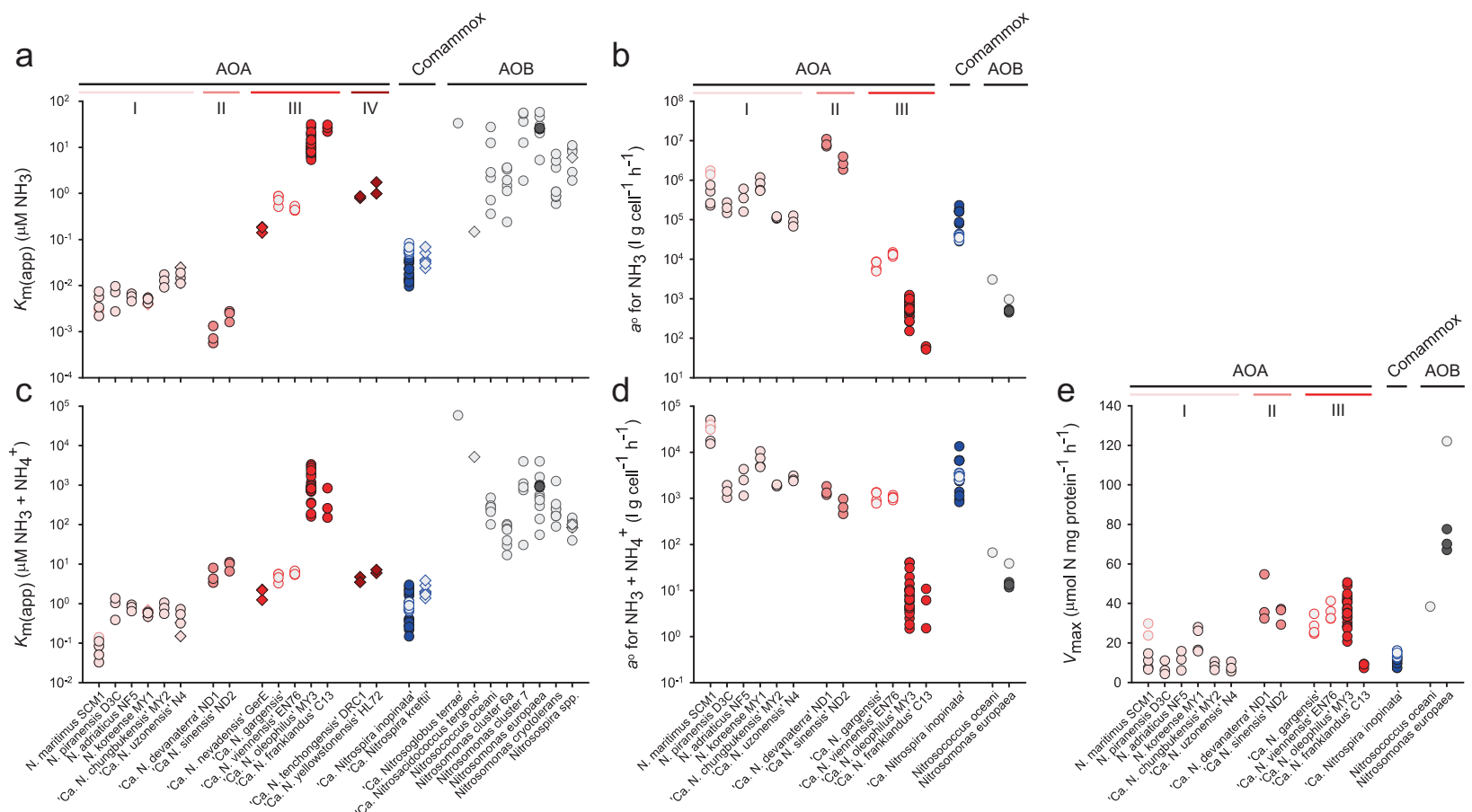

Fig. 2 Substrate-dependent oxidation kinetics of ammonia-oxidizing microorganisms. The (a) apparent substrate affinity $\left(K_{\mathrm{m}(\mathrm{app})}\right)$ for $\mathrm{NH}_{3}$, (b) specific substrate affinity $\left(a^{\circ}\right)$ for $\mathrm{NH}_{3},(\mathbf{c}) K_{\mathrm{m}(a p p)}$ for total ammonium, (d) $a^{\circ}$ for total ammonium, and (e) maximum oxidation rate $\left(V_{\text {max }}\right)$, of AOA (red), comammox (blue), and AOB (black) are provided. Symbols filled with light gray represent previously published values from reference studies (references provided in Materials and Methods). The four different gradations of red differentiate the four AOA phylogenetic lineages: (I) Nitrosopumilales, (II) 'Ca. Nitrosotaleales', (III) Nitrososphaerales, and (IV) 'Ca. Nitrosocaldales'. Measurements were performed with either pure (circles) or enrichment (diamonds) cultures. Multiple symbols per strain represent independent measurements performed in this study and/or in the literature. The individual Michaelis-Menten plots for each AOM determined in this study are presented in Figs. S1, S3-5, and S8. Note the different scales.

The moderately thermophilic enrichment culture ' $\mathrm{Ca}$. N. nevadensis' GerE displayed a higher substrate affinity (lower $K_{\mathrm{m}}$ (app) for $\mathrm{NH}_{3}(0.17 \pm 0.03 \mu \mathrm{M})$ than the other characterized $\mathrm{AOA}$ strains within the genus Nitrososphaera (Fig. 2a). In contrast, ' $\mathrm{Ca}$. N. oleophilus' MY3 and 'Ca. N. franklandus' C13, which belong to the genus Nitrosocosmicus, had the lowest affinity (highest $K_{\mathrm{m}(\mathrm{app})}$ ) for $\mathrm{NH}_{3}(12.37 \pm 6.78 \mu \mathrm{M}$ and $16.32 \pm 14.11 \mu \mathrm{M}$, respectively) of any AOA characterized to date. In fact, their substrate affinity is comparable to several characterized AOB (Fig. 2a). In this context it is interesting to note that several Nitrosocosmicus species have been shown to tolerate very high ammonium concentrations [68$70]$, a trait usually associated with $A O B[24,54]$. The low substrate affinity observed in Nitrosocosmicus AOA correlates with the absence of a putative Amt-type high affinity ammonium transporter in the genome of any sequenced Nitrosocosmicus species to date $[68,69,71]$.

'Ca. Nitrosocaldales' (Thermophilic AOA lineage). The thermophilic AOA enrichment cultures, 'Ca. Nitrosocaldus yellowstonensis' HL72 [72] and ' $C a$. N. tenchongensis' DRC1 (culture information provided in Supplementary Results and Discussion), possess affinities for $\mathrm{NH}_{3}\left(K_{\mathrm{m}(\mathrm{app})}=\sim 1.36 \pm 0.53 \mu \mathrm{M}\right.$ and $\sim 0.83 \pm 0.01 \mu \mathrm{M}$; respectively comparable to $\mathrm{AOA}$ within the genus Nitrososphaera (Fig. 2a). Notably, the substrate oxidation rate of these two AOA quickly dropped with increasing substrate concentrations after $V_{\text {max }}$ was reached (Fig. S5). This trend was not observed with any other AOA tested here and may reflect an increased susceptibly to $\mathrm{NH}_{3}$ stress at high temperatures, as the free $\mathrm{NH}_{3}$ concentration increases with increasing temperatures [33]. It should be noted that both of these AOA cultures are enrichment cultures, as no member of the ' $\mathrm{Ca}$. Nitrosocaldales' has been isolated to date.

Together, these results highlight that the substrate affinity for $\mathrm{NH}_{3}$ among AOA species is much more variable than previously hypothesized, spanning several orders of magnitude and in some cases overlapping with the substrate affinity values of characterized non-oligotrophic AOB. In addition, the substrate affinity of $A O A$ is related, to a certain degree, to their phylogenetic placement within each of the four AOA phylogenetic lineages mentioned above (Fig. 2). Although the substrate affinity ranges of these AOA lineages overlap, the link between AOA phylogeny and kinetic properties provides deeper insights into the physiological and evolutionary differences among AOA species. As a limited number of AOA have been isolated and characterized to date, the continued isolation and characterization of AOA from underrepresented phylogenetic lineages and new habitats is needed. While substrate affinity is certainly one of multiple factors that contribute to niche differentiation between AOM in general, it may also present a previously under acknowledged factor in AOA niche differentiation.

Maximum substrate oxidation rates $\left(N_{\max }\right)$. The normalized maximum substrate oxidation rate of all the AOA characterized to date only span about one order of magnitude from 4.27 to $54.68 \mu \mathrm{mol} \mathrm{N} \mathrm{mg}$ protein ${ }^{-1} \mathrm{~h}^{-1}$. These normalized AOA $V_{\max }$ values are in the same range as the recorded $V_{\max }$ for the comammox $N$. inopinata $\left(\sim 12 \mu \mathrm{mol} \mathrm{N} \mathrm{mg} \mathrm{protein}{ }^{-1} \mathrm{~h}^{-1}\right)$ and the marine AOB strain Nitrosococcus oceani ATCC $19707(\sim 38 \mu \mathrm{mol} N$ mg protein ${ }^{-1} \mathrm{~h}^{-1}$ ) but are lower than the normalized $V_{\max }$ of the AOB Nitrosomonas europaea ATCC 19718 (average of $84.2 \mu \mathrm{mol} N$ mg protein ${ }^{-1} \mathrm{~h}^{-1}$; Fig. 2e). The high $V_{\max }$ value for $N$. europaea is the only real outlier among the AOM characterized to date and it remains to be determined whether other AOB related to $N$. europaea also possess such a high $V_{\max }$ or if members of the Nitrosomonadales possess a broad range of $V_{\max }$ values. Similarly, as additional comammox strains become available as pure cultures their kinetic characterization will be vital in understanding 
the variability of these ecologically important parameters within this guild.

Specific substrate affinity $\left(a^{\circ}\right)$. Although the $K_{\mathrm{m}(\mathrm{app})}$ and $V_{\max }$ of AOM can be compared by themselves and provide useful information on cellular properties, the ability of an AOM to scavenge (and compete for) substrate from a dilute solution is most appropriately represented by the $a^{\circ}$, which takes into account both the cellular $K_{\mathrm{m}(\mathrm{app})}$ and $V_{\max }$ [28]. In previous studies, the $a^{\circ}$ of AOM has been calculated using the $K_{\mathrm{m}(\mathrm{app})}$ value for total ammonium $\left(\mathrm{NH}_{3}+\mathrm{NH}_{4}^{+}\right)$and not the $K_{\mathrm{m}(\mathrm{app})}$ value for $\mathrm{NH}_{3}[5,29]$. Calculating the $a^{\circ}$ based on the $K_{\mathrm{m}(\mathrm{app})}$ value for total ammonium allows for the $a^{\circ}$ of AOM to be compared with the $a^{\circ}$ of microorganisms that do not use $\mathrm{NH}_{3}$ as a sole energy generating substrate, such as ammonium assimilating heterotrophic bacteria or diatoms [29]. While this is useful when evaluating competition for total ammonium in mixed communities or environmental settings, an $a^{\circ}$ calculated using the $K_{\mathrm{m}(a p p)}$ value for $\mathrm{NH}_{3}$ may be more useful when directly comparing the interspecies competitiveness of AOM for the following reasons: (i) our data support the hypothesis that the substrate for all AOM is $\mathrm{NH}_{3}$ and not $\mathrm{NH}_{4}{ }^{+}$(see below) and (ii) the $K_{\mathrm{m}(\mathrm{app})}$ value for total ammonium is more dependent on the environmental factors it was measured at (e.g., $\mathrm{pH}$, temperature, salinity) than the $K_{\mathrm{m}(\mathrm{app})}$ for $\mathrm{NH}_{3}$.

All characterized AOA (with the exception of representatives of the genus Nitrosocosmicus) and the comammox bacterium $N$. inopinata possess much higher $a^{\circ}$ for total ammonium or $\mathrm{NH}_{3}$ $(\sim 10-3000 \times)$ than the AOB, N. oceani or N. europaea (Fig. 2b-d), indicating that they are highly competitive in environments limited in either total ammonium or only $\mathrm{NH}_{3}$. However, due to the low number of published normalized $V_{\max }$ values for $\mathrm{AOB}, a^{\circ}$ could only be calculated for these two AOB representatives. Thus, extrapolations to the $a^{\circ}$ of all AOB species, based solely on these observations should be approached with caution.

The low variation in experimentally measured $V_{\max }$ values (Fig. 2e) across all measured AOM in combination with the high variation in $K_{\mathrm{m}(\mathrm{app})}$ values leads to a strong relationship between cellular $a^{\circ}$ and the reciprocal of $K_{\mathrm{m}(\mathrm{app})}$ (Fig. 3) according to Eq. 2 (see Materials and Methods). AOM adapted to oligotrophic (low substrate) conditions should possess both a high substrate affinity (low $\left.K_{\mathrm{m}(\mathrm{app})}\right)$ and a high $a^{\circ}$ [28]. Therefore, the AOM best suited for environments limited in total ammonium are the AOA belonging to the Nitrosopumilales and the comammox isolate $N$. inopinata, (top right corner of Fig. 3a). Overall, when looking at solely $\mathrm{NH}_{3}$ or total ammonium, the separation of species in these plots remains similar, with the exception that the acidophilic AOA belonging to the ' $\mathrm{C} a$. Nitrosotaleales' are predicted to be best suited for life in environments limited in $\mathrm{NH}_{3}$ (Fig. 3b). The adaptation correlates well with the fact the AOA ' $\mathrm{Ca}$. Nitrosotalea devanaterra' $\mathrm{Nd} 1$ and ' $\mathrm{Ca}$. Nitrosotalea sinensis' $\mathrm{Nd} 2$ were isolated from acidic soils with a $\mathrm{pH}$ of 4.5 and 4.7 , respectively $[25,65]$, where the $\mathrm{NH}_{3}: \mathrm{NH}_{4}{ }^{+}$ equilibrium is heavily shifted toward $\mathrm{NH}_{4}{ }^{+}$.

In either case, when looking at $\mathrm{NH}_{3}$ or total ammonium, the AOA belonging to the genus Nitrosocosmicus (' $\mathrm{Ca}$. N. oleophilus' MY3 and ' $C a$. N. franklandus' $(13)$ and AOB populate the lower left section of these plots, indicating that they are not strong substrate competitors in $\mathrm{NH}_{3}$ or total ammonium limited environments (Fig. 3). Here, the $V_{\max }$ of all the AOM reported spans $\sim 10 \times$, whereas the difference in $K_{\mathrm{m}(\mathrm{app})}$ spans about five orders of magnitude. If the cellular kinetic property of $V_{\max }$ really is so similar across all AOB, AOA, and comammox species (Fig. 2e) compared to the large differences in $K_{\mathrm{m}(\mathrm{app})}$ values, then substrate competitiveness can be predicted from an AOMs $K_{\mathrm{m}(\mathrm{app})}$ for either $\mathrm{NH}_{3}$ or total ammonium (Fig. $2 \mathrm{a}-\mathrm{C}$ ). This may prove especially helpful when characterizing enrichment cultures, where normalizing ammonia-oxidizing activity to cellular protein in order to obtain a comparable $V_{\max }$ value is not possible. However, there is also a need for more kinetically characterized $A O B$ and comammox species to confirm this hypothesis. In addition, when comparing $\mathrm{AOM}$, differences in the $V_{\max }$ cellular property will play a larger role, the closer the $K_{\mathrm{m}(\mathrm{app})}$ values of the AOM strains are. This is important to consider when comparing AOM from similar habitats and likely adapted to similar substrate concentrations.

The effect of environmental and cellular factors on AOA kinetic properties. The concentration of $\mathrm{NH}_{3}$ present in a particular growth medium or environment can vary by orders of magnitude, based solely on the $\mathrm{pH}$, temperature, or salinity of the system [73]. This is notable because at a given total ammonium concentration, the concentration of $\mathrm{NH}_{3}$ is $\sim 10$ times higher at $70^{\circ} \mathrm{C}$ versus $30^{\circ} \mathrm{C}$ and $\sim 1000$ times lower at $\mathrm{pH} 5.3$ versus $\mathrm{pH} 8.4$ (representative of maximum ranges tested). While it should be recognized that in our dataset no AOM were included that have a $\mathrm{pH}$ optimum between 5.3 and 7.0, the effect of $\mathrm{pH}$ and temperature on the ammonia oxidation kinetics of AOM must be considered in order to understand their ecophysiological niches. However, there was no correlation between the kinetic properties of AOM ( $K_{\mathrm{m}(\mathrm{app}) \text {, }}$ $V_{\max }$ and $a^{\circ}$ ) measured in this study and their optimal growth temperature or $\mathrm{pH}$. This lack of correlation between AOM species kinetic properties and growth conditions does not imply that the cellular kinetic properties of an individual AOM species will remain the same over a range of $\mathrm{pH}$ and temperature conditions. Therefore, we investigated the effect of $\mathrm{pH}$ and temperature variation on the substrate-dependent kinetic properties of the AOA strain ' $\mathrm{Ca}$. N. oleophilus' MY3, and the effect of pH on the comammox strain $\mathrm{N}$. inopinata. Here, the AOA ' $\mathrm{Ca}$. N. oleophilus' MY3 was selected based on the fact that it is a non-marine, mesophilic, pure culture, that does not require external hydrogen peroxide scavengers for growth. These traits are shared with the previously characterized AOB, N. europaea [35], and the comammox organism, $N$. inopinata (this study) and thus facilitate comparison.

The effect of temperature. The effects of short-term temperature changes on the substrate-dependent kinetic properties of ' $\mathrm{Ca} . \mathrm{N}$. oleophilus' MY3 were determined. Temperature shifts of $5^{\circ} \mathrm{C}$ above and below the optimal growth temperature $\left(30^{\circ} \mathrm{C}\right)$ had no effect on the $K_{\mathrm{m}(\mathrm{app})}$ for total ammonium. However, the $K_{\mathrm{m}(\text { app })}$ for $\mathrm{NH}_{3}, V_{\text {max }}$ and $a^{\circ}$ of ' $\mathrm{C} a$. N. oleophilus' MY3 all increased with increasing temperatures (Fig. S6). Therefore, as temperature increased, 'C $a$. N. oleophilus' MY3 displayed a lower substrate affinity (higher $K_{\mathrm{m}(\mathrm{app})}$ for $\mathrm{NH}_{3}$ ) but would be able to turnover substrate with a higher $V_{\max }$ and better compete for substrate with a higher $a^{\circ}$. Increasing AOA $K_{m(a p p)}$ values for $\mathrm{NH}_{3}$ with increasing temperatures have also been observed across studies with $N$. viennensis EN76 (Fig. S2), and this is discussed in more detail in the Supplementary Results and Discussion. In addition, similar observations have previously been made for AOB strains belonging to the genus Nitrosomonas $[33,34]$. The increase in $V_{\max }$ and $a^{\circ}$ can be explained in terms of the Van't Hoff rule (reaction velocity increases with temperature) [74], or in terms of a temperature sensitivity coefficient $\left(Q_{10}\right.$; change in reaction velocity over $10^{\circ} \mathrm{C}$ ) [75]. Here, the maximal reaction velocity of 'Ca. N. oleophilus' MY3, displays a relative $Q_{10}$ of 2.17 between 25 and $35^{\circ} \mathrm{C}$, which is in line with more general microbial respiration measurements $[75,76]$.

The increase in $K_{\mathrm{m} \text { (app) }}$ for $\mathrm{NH}_{3}$ (lower $\mathrm{NH}_{3}$ affinity) with increasing temperature is less straightforward to interpret. As this is a whole cell measurement, the observed differences may result from either broad cellular changes or from changes in individual enzymes involved in the ammonia oxidation pathway specifically. At the cellular level, changes in the proteinaceous surface layer ( $\mathrm{S}$ layer) or lipid cell membrane could affect substrate movement/ transport and enzyme complex stability. It has been suggested that the negatively charged AOA S-layer proteins act as a substrate reservoir, trapping $\mathrm{NH}_{4}^{+}$and consequently increasing 
a

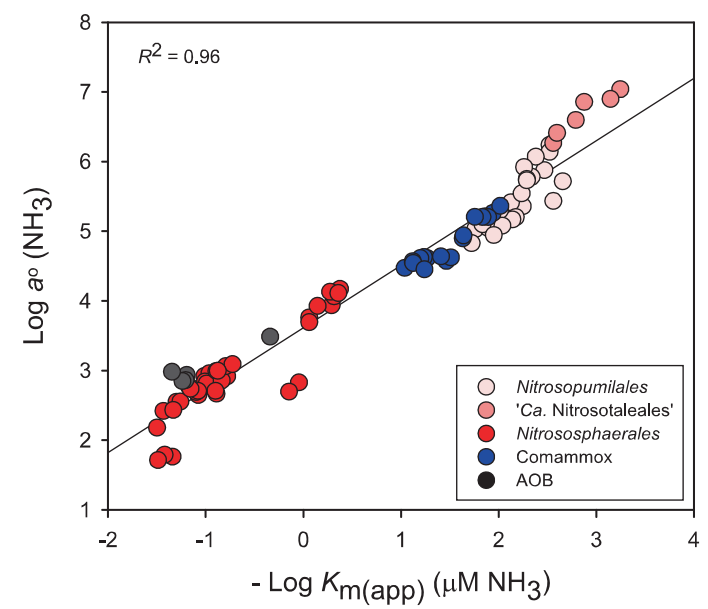

b

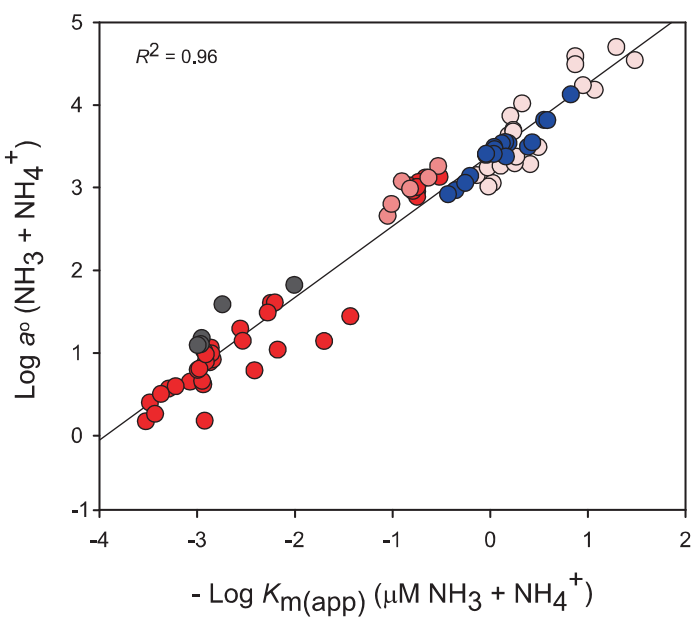

Fig. 3 The reciprocal relationship between the substrate affinity $\left(K_{\mathrm{m}(a p p)}\right)$ and specific substrate affinity $\left(a^{\circ}\right)$ of ammonia-oxidizing microorganisms (AOM). Reciprocal plots for both (a) total ammonium and (b) $\mathrm{NH}_{3}$ are depicted. The $K_{\mathrm{m}(\mathrm{app})}$ and $a^{\circ}$ values correspond to the values presented for pure AOM isolates in Fig. 2. Data for AOA (red), comammox (blue), and AOB (black) are shown. The correlation ( $R^{2}$ ) indicates the linear relationship between the logarithmically transformed data points.

the $\mathrm{NH}_{3}$ concentration in the AOA pseudo-periplasmic space [77]. It is interesting to note that sequenced representatives from the genus 'Ca. Nitrosocosmicus' lack the main S-layer protein (slp1) found in all Nitrosopumilales, Nitrososphaerales, and 'Ca. Nitrosotaleales' sequenced isolates [71], although it remains to be demonstrated whether ' $\mathrm{C}$ a. Nitrosocosmicus' members actually lack a S-layer or form S-layers composed of other proteins. In addition, it has been demonstrated that elevated temperatures significantly alter the lipid composition in the AOA cell membrane $[78,79]$. However, it is unclear how differences in the cell membrane or S-layer composition between AOA species may affect the observed kinetic properties. In this context it is important to note that on the single enzyme level, previous studies have shown the same trend of decreasing substrate affinity and increasing maximal reaction velocity with increasing temperatures, due to altered protein structures and an increased enzyme-substrate dissociation constant $[80,81]$.

Notably, differing optimum growth and activity conditions were previously determined for the marine AOB strain Nitrosomonas cryotolerans [34]. These observations raise interesting, albeit unanswered, questions about why the growth and activity temperature optima are or can be uncoupled in AOM, and what this means for AOM niche differentiation and their competitiveness in-situ. Moving forward, investigations into the growth and cellular kinetic properties of AOM across a range of environmental factor gradients will be essential in understanding competition between AOM in engineered and environmental systems.

The effect of $\mathrm{pH}$. The effects of short-term $\mathrm{pH}$ changes on the substrate-dependent kinetics of ' $\mathrm{C} a$. $\mathrm{N}$. oleophilus' MY3 and $\mathrm{N}$. inopinata were determined. The $V_{\max }$ of both ' $\mathrm{Ca}$. N. oleophilus MY3' and $N$. inopinata were stable at $37.3 \pm 6.6 \mu \mathrm{mol} N \mathrm{mg}$ protein $^{-1} \mathrm{~h}^{-1}$ and $11.2 \pm 2.5 \mu \mathrm{mol} \mathrm{N} \mathrm{mg} \mathrm{protein}{ }^{-1} \mathrm{~h}^{-1}$, respectively, in medium with a pH between $\sim 6.5$ and $\sim 8.5$ (Table S3). The $K_{\mathrm{m}(\mathrm{app})}$ for total ammonium of ' $\mathrm{C} a$. N. oleophilus $\mathrm{MY}^{\prime}$ ' and $N$. inopinata decreased by more than an order of magnitude $(\sim 11 \times)$ across this $\mathrm{pH}$ range, while the $K_{\mathrm{m}(\mathrm{app})}$ for $\mathrm{NH}_{3}$ remained more stable, increasing only 3-4 times (Fig. 4). This stability of the $K_{\mathrm{m}}$ (app) for $\mathrm{NH}_{3}$ compared with the larger change in the $K_{\mathrm{m}(\mathrm{app})}$ for total ammonium across this $\mathrm{pH}$ range suggests that the actual substrate used by AOA and comammox is indeed the undissociated form $\left(\mathrm{NH}_{3}\right)$ rather than the ammonium ion $\left(\mathrm{NH}_{4}{ }^{+}\right)$, as previously demonstrated for $A O B$ [34, 35, 54, 82]. As these kinetic measurements were performed with whole cells, the change in $K_{\mathrm{m}}$ (app) for $\mathrm{NH}_{3}$ across this $\mathrm{pH}$ range may be due to cellular effects of the differing $\mathrm{pH}$ values unrelated to the direct ammonia oxidation pathway. The changes in $\mathrm{Km}_{(\mathrm{app})}$ for $\mathrm{NH}_{3}$ and $K_{\mathrm{m}(\mathrm{app})}$ for total ammonium demonstrated here for ' $\mathrm{C} a$. N. oleophilus' MY3 and $N$. inopinata are similar to what has been observed for $\mathrm{AOB}$. That AOA and $A O B$ utilize the $\mathrm{NH}_{3}$ as a substrate, aligns with the fact that both are competitively inhibited by the non-polar acetylene compound [83, 84].

Interestingly, the only exception to this rule to date is the gammaproteobacterial marine AOB Nitrosococcus oceani. The reported $K_{\mathrm{m}(\mathrm{app})}$ for total ammonium of $N$. oceani remained more stable $(\sim 2.3 \times)$ than the $K_{\mathrm{m}(\mathrm{app})}$ for $\mathrm{NH}_{3}(78 \times)$ when the $\mathrm{pH}$ was shifted from 6.3 to 8.6 [85]. With this exception in mind, our results support the hypothesis that $A O A, A O B$, and comammox utilize $\mathrm{NH}_{3}$ as their substrate. As only a few AOM have been characterized in this manner, the characterization of a more diverse set of AOM species is needed in order to make broader conclusions.

It is important to note that the substrate affinities reported here represent whole cell affinities and not the substrate affinity of ammonia monooxygenase (AMO) enzymes. Therefore, further experimental investigation with purified $\mathrm{AMO}$ and ammonia/ ammonium transporter proteins is warranted. Although $\mathrm{NH}_{3}$ can freely diffuse passively into AOM, this does not mean that the cellular affinity reported here is necessarily unrelated to the transporter-mediated movement of $\mathrm{NH}_{3} / \mathrm{NH}_{4}{ }^{+}$into AOM cells. For example, $A O B$ have previously been shown to accumulate very high (1 M) intracellular $\mathrm{NH}_{4}^{+}$concentrations [86]. This high intracellular $\mathrm{NH}_{4}^{+}$concentration may provide a concentrated substrate reservoir, indirectly increasing the concentration of $\mathrm{NH}_{3}$ around the AMO enzyme complex. In addition, the negatively charged S-layer of $N$. maritimus has been shown to act as a substrate reservoir for the positively charged $\mathrm{NH}_{4}{ }^{+}$. This total ammonium concentration in the pseudo-periplasmic space of AOA, may also act to indirectly increase $\mathrm{NH}_{3}$ concentrations around the AMO enzyme complex [77]. However, the impact of total ammonium capture and transport on the ammonia oxidation kinetic properties of $A O B, A O A$, and comammox are not yet well understood. It is unknown if such a concentration mechanism would be more important for an $A O B$ with a low substrate affinity (e.g., N. europaea) or for an AOA living in extremely substratelimited environments (e.g., N. maritimus). 

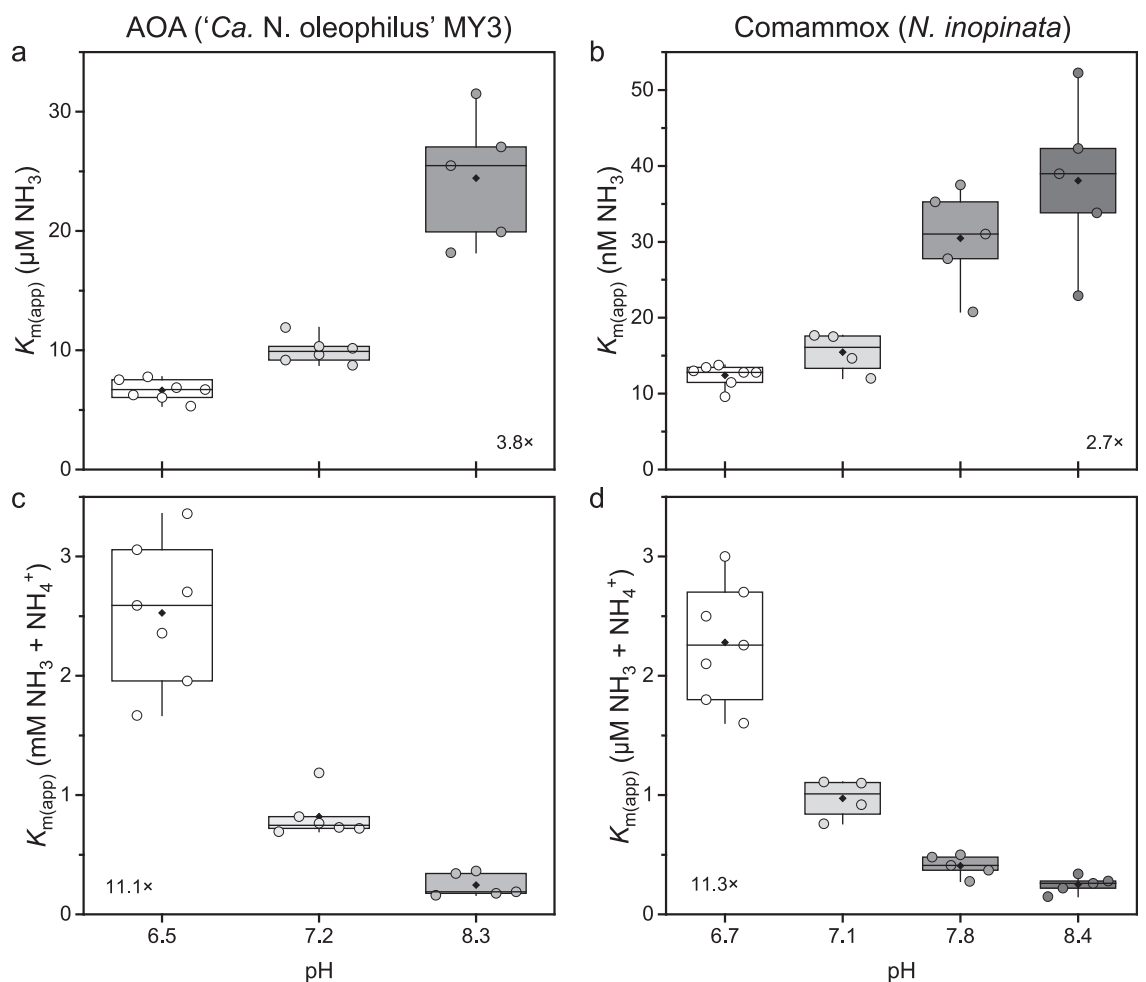

Fig. 4 The effect of medium pH on the substrate affinity of ' $\mathbf{C a}$. N. oleophilus MY3' and $\mathbf{N}$. inopinata. The substrate affinities for both (a,b) $\mathrm{NH}_{3}$ and (c,d) total ammonium $\left(\mathrm{NH}_{3}+\mathrm{NH}_{4}{ }^{+}\right)$are provided. Individual substrate affinity values determined at each pH are shown as single points (circles). The boxes represent the first and third quartiles (25-75\%) of the substrate affinity range under each condition. The median (line within the boxes) and mean substrate affinity (black diamonds) values are also indicated. The whiskers represent the most extreme values within 1.58x of quartile range. The variation of the substrate affinity values across the entire tested pH range are indicated in each panel. In all four instances there was a significant difference between the affinity at the lowest $\mathrm{pH}$ and the highest $\mathrm{pH}$, as determined by a Student's $t$ test $(p<0.005)$. The average substrate affinity values for ' $\mathrm{C} a$. N. oleophilus MY3' and $\mathrm{N}$. inopinata at each $\mathrm{pH}$ are provided in Table S3.

The effect of cell morphology. All AOM share the primary enzyme involved in ammonia oxidation, AMO, which is located in the cytoplasmic membrane with its substrate-binding site most likely facing the outside of the cell [77]. Therefore, a higher cellular SA/V ratio likely contributes to an increase in $a^{\circ}$, as it increases the space available for $\mathrm{AMO}$ and the chance to bind $\mathrm{NH}_{3}$ at very low concentrations. This assumption is based on the hypothesis that an increased abundance of uptake enzymes (e.g., permeases) leads to a higher $a^{\circ}[28,56]$. In fact, the SA/V ratio of AOM (Table S4) correlates to the log of their observed $K_{\mathrm{m} \text { (app) }}$ for $\mathrm{NH}_{3}$ $\left(R^{2}=0.88\right), K_{\mathrm{m}(\mathrm{app})}$ for total ammonium $\left(R^{2}=0.70\right), a^{\circ}$ for $\mathrm{NH}_{3}$ $\left(R^{2}=0.78\right)$, and $a^{\circ}$ for total ammonium $\left(R^{2}=0.72 ;\right.$ Fig. 5). This type of casual semi-log relationship between cell size and nutrient affinities has previously been observed between microorganisms and their affinity for phosphate [87] as well as theoretically modeled for nutrient uptake and utilization in general [88]. Therefore, the SA/ $V$ ratio of newly cultured $A O M$ might be a useful general indicator for these cellular kinetic properties. Consequently, AOM with a high SA/V ratio will likely outcompete other AOM in many natural aquatic and terrestrial environments, such as the pelagic marine water column that has a very low standing total ammonium pool. Consistently, these oligotrophic environments have already been postulated to select for organisms with a high SAN ratio, enhancing their nutrient uptake capabilities $[89,90]$.

The correlation between the SA/V ratio and cellular kinetic properties of AOM sheds some light on the unusual kinetic properties of the AOA belonging to the genus Nitrosocosmicus. Both ' $\mathrm{C} a$. N. oleophilus' MY3 and ' $\mathrm{C}$. N. franklandus' $\mathrm{C} 13$ possess a very low SA/V ratio compared to other $A O A$ isolates and they both possess several characteristics normally associated with $A O B$ - high substrate tolerances [68-70], low affinities for $\mathrm{NH}_{3}$, and a low $a^{\circ}$ for
$\mathrm{NH}_{3}$-that are not consistent with the long-held convention that all AOA are much stronger competitors for $\mathrm{NH}_{3}$ than $\mathrm{AOB}$ in substratelimited environments. Therefore, the individual cell morphology of AOM may have a direct relationship with their cellular kinetic properties. Although this is only a correlation-based observation, it highlights that further investigation into these characteristics is warranted.

In addition to cellular morphology, the size of cell aggregates can affect the kinetic properties of AOM [48]. Cell aggregates have a lower SA/V ratio than individual cells, which can decrease diffusion rates and create microscale substrate/oxygen gradients within aggregates [91]. In order to ensure that the large differences in substrate affinity among AOA are not caused by differences in cell aggregation, the aggregate size of ' $\mathrm{C} a$. N. uzonensis' $\mathrm{N} 4$, ' $\mathrm{Ca}$. $\mathrm{N}$. oleophilus' MY3, and N. piranensis D3C cultures were inspected before and after MR experiments (Fig. S7).

These three AOA were chosen to highlight the aggregate sizes observed in cultures that displayed the lowest (' $\mathrm{Ca}$. N. oleophilus' MY3) and among the highest (' $\mathrm{Ca}$. N. uzonensis' N4 and N. piranensis D3C) substrate affinities. No aggregation pattern was observed that would explain the multiple orders of magnitude differences in substrate affinity between these AOA. In fact, of the three AOA investigated, the only strain to form large cell aggregates either before or after MR experiments was $N$. piranensis D3C, which has one of the highest measured substrate affinities (lowest $K_{\mathrm{m}(a p p)}$ for $\mathrm{NH}_{3}$ ). In contrast, the cell aggregate size of ' $\mathrm{Ca}$. N. oleophilus' MY3 and ' $\mathrm{Ca}$. N. uzonensis' N4 were unaffected by the MR experiment and remained relatively small (Fig. S7). As ' $\mathrm{C}$. N. N. oleophilus' MY3 has one of the lowest substrate affinities (highest $K_{\mathrm{m}(\mathrm{app})}$ for $\mathrm{NH}_{3}$ ) and formed only small cell aggregates, the low substrate affinity of ' $\mathrm{Ca}$. 

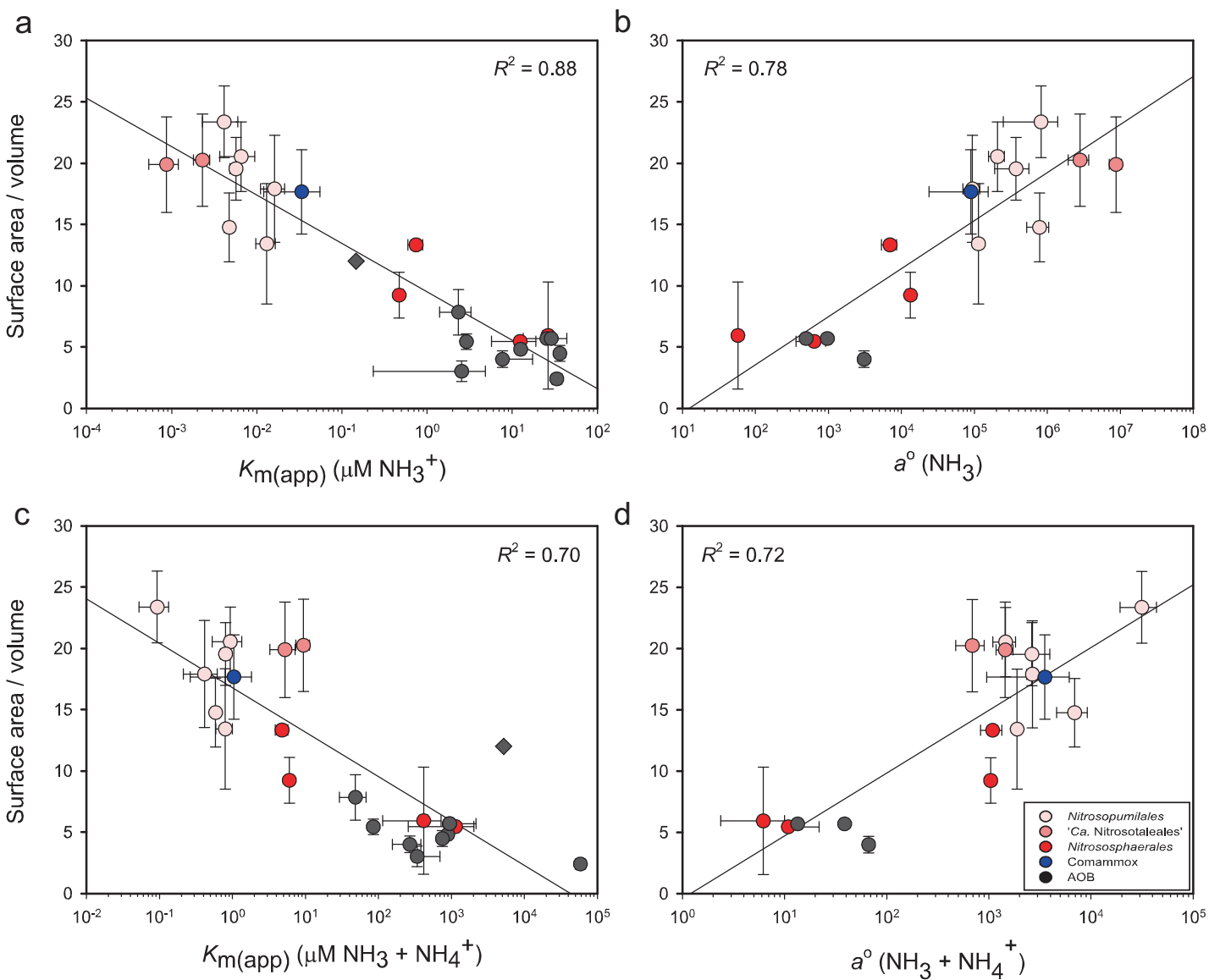

Fig. 5 Logarithmic correlation of the substrate affinity $\left(K_{\mathrm{m}(\mathrm{app})}\right)$ and specific substrate affinity $\left(a^{\circ}\right)$ with the cellular surface area to volume ratio of ammonia-oxidizing microorganisms $(\mathbf{A O M})$. All $K_{\mathrm{m}(\mathrm{app})}(\mathbf{a}, \mathbf{c})$ and $a^{\circ}(\mathbf{b}, \mathbf{d})$ values correspond to values presented in Fig. 2. The surface area to volume (SA/V) ratio calculations for each AOM are provided in Table S4. Data for AOA (red), comammox (blue), and AOB (black) are shown. The three different gradations of red differentiate three distinct AOA phylogenetic lineages. The error bars represent the standard deviation of replicate kinetic experiments or SA/N ratio measurements of each AOM strain. The logarithmic correlation $\left(R^{2}\right)$ value was calculated from the average values of each AOM and is presented on a semi-log axis.

N. oleophilus' MY3 was not an artefact caused by cell aggregation.

Taken together, both environmental ( $\mathrm{pH}$ and temperature) and AOM cellular (SAN ratio) factors affect or are related to the observable cellular kinetic properties of individual AOM species. These factors need to be considered when investigating AOM competition or niche differentiation in-situ, as they are often in flux in environmental settings. This can be especially true considering cell morphology, which is often dependent on growth conditions [92]. However, the plasticity of the cellular kinetic properties within individual AOM species does not explain the larger trends observed here across AOA lineages or between AOM (Figs. 2, S1, S3-5, S8).

\section{CONCLUDING REMARKS}

In this study we substantially extended the set of available substrate oxidation kinetic properties for AOA by the analysis of pure cultures or enrichments from various lineages within this guild. Furthermore, our kinetic data obtained at different $\mathrm{pH}$ values supports the hypothesis that, like for $A O B$, the substrate for $\mathrm{AOA}$ and comammox is $\mathrm{NH}_{3}$. Together, our findings provide novel insights for our understanding of niche differentiation among $\mathrm{AOM}$ and demonstrate a surprising variability of the inferred kinetic properties among AOA. Thus, our data strengthens the recent discovery [5] that not all AOA possess an extremely high substrate affinity or specific substrate affinity. The observed links between AOA kinetic properties, phylogeny, and cell morphology also enables the formulation of testable hypotheses on nitrification kinetics in systems thus far characterized solely with molecular (e.g., amplicon sequencing or metagenomic) tools.

As environmental factors such as temperature and $\mathrm{pH}$ influence kinetic properties of AOA including their cellular affinity for $\mathrm{NH}_{3}$, future analyses of kinetic properties of AOM should not only be performed at their optimal growth conditions, but also over a range of conditions that reflect their environmental niches. Such experiments will generate a more informative picture on AOM competition and niche differentiation.

\section{Newly isolated Nitrosotenuis species}

The isolated strain N4 is a novel species of the genus Nitrosotenuis of the order Nitrosopumilales, and we propose the following candidate status:

Taxonomy.

(i) Etymology. The taxonomy for 'Candidatus Nitrosotenuis uzonensis' sp. nov. is as follows: Nitrosus (Latin masculine adjective), nitrous; tenuis (Latin masculine adjective), small/ slender; uzonensis (Latin neutrum genitive), from Uzon.

(ii) Locality. A terrestrial thermal spring located in the Uzon caldera on the Kamchatka peninsula, Russia.

(iii) Diagnosis. A chemolithoautotrophic ammonia oxidizer of the phylum Thaumarchaeota, which is straight and rodshaped, with a diameter of $0.2-0.3 \mu \mathrm{m}$ and a length of 0.4-1.7 $\mu \mathrm{m}$. Growth over a period of several years has been 
maintained in a medium with a pH of 7.5 at $37^{\circ} \mathrm{C}$. It belongs to the AOA order Nitrosopumilales (group I.1a). AOA with almost identical $16 \mathrm{~S}$ rRNA and $a m o A$ gene sequences have been detected in various environments, including soil and groundwater $[22,40,62]$.

\section{REFERENCES}

1. Ward BB, Arp DJ, Klotz MG. Nitrification. Washington, D.C.: American Society of Microbiology; 2011.

2. Kuypers MMM, Marchant HK, Kartal B. The microbial nitrogen-cycling network. Nat Rev Microbiol. 2018;16:263-76.

3. Könneke $M$, Bernhard $A E$, de la Torre JR, Walker $C B$, Waterbury JB, Stahl DA. Isolation of an autotrophic ammonia-oxidizing marine archaeon. Nature. 2005;437:543-6.

4. Treusch AH, Leininger S, Kletzin A, Schuster SC, Klenk HP, Schleper C. Novel genes for nitrite reductase and Amo-related proteins indicate a role of uncultivated mesophilic crenarchaeota in nitrogen cycling. Environ Microbiol. 2005;7:1985-95.

5. Kits KD, Sedlacek CJ, Lebedeva EV, Han P, Bulaev A, Pjevac P, et al. Kinetic analysis of a complete nitrifier reveals an oligotrophic lifestyle. Nature. 2017;549:269-72.

6. van Kessel MA, Speth DR, Albertsen M, Nielsen PH, Op den Camp HJ, Kartal B, et al. Complete nitrification by a single microorganism. Nature. 2015;528:555-9.

7. Daims H, Lebedeva EV, Pjevac P, Han P, Herbold C, Albertsen M, et al. Complete nitrification by Nitrospira bacteria. Nature. 2015;528:504-9.

8. Leininger S, Urich T, Schloter M, Schwark L, Qi J, Nicol GW, et al. Archaea predominate among ammonia-oxidizing prokaryotes in soils. Nature. 2006:442:806-9.

9. Verhamme DT, Prosser Jl, Nicol GW. Ammonia concentration determines differential growth of ammonia-oxidising archaea and bacteria in soil microcosms. ISME J. 2011;5:1067-71.

10. Wuchter $C$, Abbas B, Coolen MJ, Herfort $L$, van Bleijswijk J, Timmers $P$, et al. Archaeal nitrification in the ocean. Proc Natl Acad Sci USA. 2006;103:12317-22.

11. Yang $Y$, Zhang J, Zhao Q, Zhou Q, Li N, Wang $Y$, et al. Sediment ammoniaoxidizing microorganisms in two plateau freshwater lakes at different trophic states. Microb Ecol. 2016;71:257-65.

12. Fan F, Yang Q, Li Z, Wei D, Cui X, Liang Y. Impacts of organic and inorganic fertilizers on nitrification in a cold climate soil are linked to the bacterial ammonia oxidizer community. Microb Ecol. 2011;62:982-90.

13. Bollmann A, Bullerjahn GS, McKay RM. Abundance and diversity of ammoniaoxidizing archaea and bacteria in sediments of trophic end members of the Laurentian Great Lakes, Erie and Superior. PLoS ONE. 2014;9:e97068.

14. Mußmann M, Brito I, Pitcher A, Sinninghe Damsté JS, Hatzenpichler R, Richter A, et al. Thaumarchaeotes abundant in refinery nitrifying sludges express amoA but are not obligate autotrophic ammonia oxidizers. Proc Natl Acad Sci USA 2011;108:16771-6.

15. Wang $Y$, Ma L, Mao Y, Jiang X, Xia Y, Yu K, et al. Comammox in drinking water systems. Water Res. 2017;116:332-41.

16. Pjevac P, Schauberger C, Poghosyan L, Herbold CW, van Kessel M, Daebeler A, et al. AmoA-targeted polymerase chain reaction primers for the specific detection and quantification of comammox Nitrospira in the environment. Front Microbiol. 2017:8:1508.

17. Fowler SJ, Palomo A, Dechesne A, Mines PD, Smets BF. Comammox Nitrospira are abundant ammonia oxidizers in diverse groundwater-fed rapid sand filter communities. Environ Microbiol. 2018;20:1002-15.

18. Roots P, Wang Y, Rosenthal AF, Griffin JS, Sabba F, Petrovich M, et al. Comammox Nitrospira are the dominant ammonia oxidizers in a mainstream low dissolved oxygen nitrification reactor. Water Res. 2019;157:396-405.

19. Xia F, Wang JG, Zhu T, Zou B, Rhee SK, Quan ZX. Ubiquity and diversity of complete ammonia oxidizers (Comammox). Appl Environ Microbiol. 2018;84: e01390-18.

20. Prosser Jl, Nicol GW. Archaeal and bacterial ammonia-oxidisers in soil: the quest for niche specialisation and differentiation. Trends Microbiol. 2012;20:523-31.

21. Schleper C. Ammonia oxidation: different niches for bacteria and archaea? ISME J. 2010;4:1092-4.

22. French E, Kozlowski JA, Mukherjee M, Bullerjahn G, Bollmann A. Ecophysiological characterization of ammonia-oxidizing archaea and bacteria from freshwater. Appl Environ Microbiol. 2012;78:5773-80.

23. Merbt SN, Stahl DA, Casamayor EO, Marti E, Nicol GW, Prosser Jl. Differential photoinhibition of bacterial and archaeal ammonia oxidation. FEMS Microbiol Lett. 2012;327:41-6.

24. Jung MY, Park SJ, Min D, Kim JS, Rijpstra WI, Sinninghe Damsté JS, et al. Enrichment and characterization of an autotrophic ammonia-oxidizing archaeon of mesophilic crenarchaeal group I.1a from an agricultural soil. Appl Environ Microbiol. 2011;77:8635-47.

25. Lehtovirta-Morley LE, Ge C, Ross J, Yao H, Nicol GW, Prosser J. Characterisation of terrestrial acidophilic archaeal ammonia oxidisers and their inhibition and stimulation by organic compounds. FEMS Microbiol Ecol. 2014;89:542-52.

26. Sedlacek CJ, Giguere AT, Dobie MD, Mellbye BL, Ferrell RV, Woebken D et al. Transcriptomic response of Nitrosomonas europaea transitioned from ammoniato oxygen-limited steady-state growth. mSystems. 2020;5:e00562-19.

27. Gwak J-H, Jung M-Y, Hong H, Kim J-G, Quan Z-X, Reinfelder JR, et al. Archaeal nitrification is constrained by copper complexation with organic matter in municipal wastewater treatment plants. ISME J. 2020;14:335-46.

28. Button DK. Biochemical basis for whole-cell uptake kinetics: specific affinity, oligotrophic capacity, and the meaning of the michaelis constant. Appl Environ Microbiol. 1991;57:2033-8.

29. Martens-Habbena W, Berube PM, Urakawa H, de la Torre JR, Stahl DA. Ammonia oxidation kinetics determine niche separation of nitrifying archaea and bacteria. Nature. 2009;461:976-9.

30. Hatzenpichler R. Diversity, physiology, and niche differentiation of ammoniaoxidizing archaea. Appl Environ Microbiol. 2012;78:7501-10.

31. Aigle A, Gubry-Rangin C, Thion C, Estera-Molina KY, Richmond H, Pett-Ridge J, et al. Experimental testing of hypotheses for temperature- and $\mathrm{pH}$-based niche specialization of ammonia oxidizing archaea and bacteria. Environ Microbiol. 2020;22:4032-45.

32. Taylor AE, Giguere AT, Zoebelein CM, Myrold DD, Bottomley PJ. Modeling of soil nitrification responses to temperature reveals thermodynamic differences between ammonia-oxidizing activity of archaea and bacteria. ISME J. 2017;11:896-908.

33. Groeneweg J, Sellner B, Tappe W. Ammonia oxidation in Nitrosomonas at $\mathrm{NH}_{3}$ concentrations near $K_{\mathrm{m}}$ : effects of $\mathrm{pH}$ and temperature. Water Res. 1994;28:2561-6.

34. Jones RD, Morita RY. Low-temperature growth and whole-cell kinetics of a marine ammonium oxidizer. Mar Ecol Prog Ser. 1985;21:239-43.

35. Suzuki I, Dular U, Kwok SC. Ammonia or ammonium ion as substrate for oxidation by Nitrosomonas europaea cells and extracts. J Bacteriol. 1974;120:556-8.

36. Kandeler E, Gerber H. Short-term assay of soil urease activity using colorimetric determination of ammonium. Biol Fert Soils. 1988;6:68-72.

37. Hood-Nowotny R, Umana NH-N, Inselbacher E, Oswald-Lachouani P, Wanek W. Alternative methods for measuring inorganic, organic, and total dissolved nitrogen in soil. Soil Sci Soc Am J. 2010;74:1018-27.

38. Miranda KM, Espey MG, Wink DA. A rapid, simple spectrophotometric method for simultaneous detection of nitrate and nitrite. Nitric Oxide. 2001;5:62-71.

39. Kits KD, Jung MY, Vierheilig J, Pjevac P, Sedlacek CJ, Liu S, et al. Low yield and abiotic origin of $\mathrm{N}_{2} \mathrm{O}$ formed by the complete nitrifier Nitrospira inopinata. Nat Commun. 2019;10:1836.

40. Lebedeva EV, Hatzenpichler R, Pelletier E, Schuster N, Hauzmayer S, Bulaev A et al. Enrichment and genome sequence of the group I.1a ammonia-oxidizing Archaeon " $\mathrm{Ca}$. Nitrosotenuis uzonensis" representing a clade globally distributed in thermal habitats. PLoS ONE. 2013;8:e80835.

41. Parks DH, Chuvochina $M$, Chaumeil PA, Rinke $C$, Mussig AJ, Hugenholtz P. A complete domain-to-species taxonomy for Bacteria and Archaea. Nat Biotechnol. 2020;38:1079-86.

42. Parks DH, Imelfort $M$, Skennerton CT, Hugenholtz $P$, Tyson GW. CheckM: assessing the quality of microbial genomes recovered from isolates, single cells, and metagenomes. Genom Res. 2015;25:1043-55.

43. Nguyen LT, Schmidt HA, von Haeseler A, Minh BQ. IQ-TREE: a fast and effective stochastic algorithm for estimating maximum-likelihood phylogenies. Mol Biol Evol. 2015;32:268-74.

44. Kalyaanamoorthy $S$, Minh BQ, Wong TKF, von Haeseler A, Jermiin LS. ModelFinder: fast model selection for accurate phylogenetic estimates. Nat Methods. 2017;14:587-9.

45. Minh $B Q$, Nguyen MA, von Haeseler A. Ultrafast approximation for phylogenetic bootstrap. Mol Biol Evol. 2013;30:1188-95.

46. Martens-Habbena W, Stahl DA. Nitrogen metabolism and kinetics of ammoniaoxidizing archaea. Methods Enzymol. 2011;496:465-87.

47. Lukumbuzya $M$, Kristensen JM, Kitzinger $K$, Pommerening-Roser $A$, Nielsen $\mathrm{PH}_{\text {, }}$ Wagner $M$, et al. A refined set of rRNA-targeted oligonucleotide probes for in situ detection and quantification of ammonia-oxidizing bacteria. Water Res. 2020;186:116372

48. Sakoula D, Koch H, Frank J, Jetten MSM, van Kessel M, Lucker S. Enrichment and physiological characterization of a novel comammox Nitrospira indicates ammonium inhibition of complete nitrification. ISME J. 2020;15:1010-24.

49. Kemmer G, Keller S. Nonlinear least-squares data fitting in Excel spreadsheets. Nat Protoc. 2010;5:267-81. 
50. Clegg SL, Whitfield M. A chemical model of seawater including dissolved ammonia and the stoichiometric dissociation constant of ammonia in estuarine water and seawater from -2 to $40^{\circ} \mathrm{C}$. Geochim Cosmochim Acta. 1995;59:2403-21.

51. Koper TE, Stark JM, Habteselassie MY, Norton JM. Nitrification exhibits Haldane kinetics in an agricultural soil treated with ammonium sulfate or dairy-waste compost. FEMS Microbiol Ecol. 2010;74:316-22.

52. Koops H-P, Pommerening-Röser A. Distribution and ecophysiology of the nitrifying bacteria emphasizing cultured species. FEMS Microbiol Ecol. 2001;37:1-9.

53. Bollmann A, Bar-Gilissen MJ, Laanbroek HJ. Growth at low ammonium concentrations and starvation response as potential factors involved in niche differentiation among ammonia-oxidizing bacteria. Appl Environ Microbiol. 2002;68:4751-7.

54. Hunik JH, Meijer HJG, Tramper J. Kinetics of Nitrosomonas europaea at extreme substrate, product and salt concentrations. Appl Microbiol Biotechnol. 1992;37:802-7.

55. Picone N, Pol A, Mesman R, van Kessel M, Cremers G, van Gelder AH et al. Ammonia oxidation at $\mathrm{pH} 2.5$ by a new gammaproteobacterial ammoniaoxidizing bacterium. ISME J. 2020;15:1150-64.

56. Button DK. Nutrient uptake by microorganisms according to kinetic parameters from theory as related to cytoarchitecture. Microbiol Mol Biol Rev. 1998;62:636-45.

57. Sliusarenko O, Heinritz J, Emonet $\mathrm{T}$, Jacobs-Wagner C. High-throughput, subpixel precision analysis of bacterial morphogenesis and intracellular spatio-temporal dynamics. Mol Microbiol. 2011;80:612-27.

58. Pester M, Rattei T, Flechl S, Grongroft A, Richter A, Overmann J, et al. amoA-based consensus phylogeny of ammonia-oxidizing archaea and deep sequencing of $a m o A$ genes from soils of four different geographic regions. Environ Microbiol. 2012;14:525-39.

59. Alves RJE, Minh BQ, Urich T, von Haeseler A, Schleper C. Unifying the global phylogeny and environmental distribution of ammonia-oxidising archaea based on $a m o A$ genes. Nat Commun. 2018;9:1517.

60. Bayer B, Vojvoda J, Reinthaler T, Reyes C, Pinto M, Herndl GJ. Nitrosopumilus adriaticus sp. nov. and Nitrosopumilus piranensis sp. nov., two ammonia-oxidizing archaea from the Adriatic Sea and members of the class Nitrososphaeria. Int J Syst Evol Microbiol. 2019;69:1892-902.

61. Jung MY, Islam MA, Gwak JH, Kim JG, Rhee SK. Nitrosarchaeum koreense gen. nov., sp. nov., an aerobic and mesophilic, ammonia-oxidizing archaeon member of the phylum Thaumarchaeota isolated from agricultural soil. Int J Syst Evol Microbiol. 2018;68:3084-95.

62. Jung MY, Park SJ, Kim SJ, Kim JG, Sinninghe Damsté JS, Jeon CO, et al. A mesophilic, autotrophic, ammonia-oxidizing archaeon of thaumarchaeal group I.1a cultivated from a deep oligotrophic soil horizon. Appl Environ Microbiol. 2014;80:3645-55.

63. Hink L, Lycus P, Gubry-Rangin C, Frostegard A, Nicol GW, Prosser Jl, et al. Kinetics of $\mathrm{NH}_{3}$-oxidation, $\mathrm{NO}$-turnover, $\mathrm{N}_{2} \mathrm{O}$-production and electron flow during oxygen depletion in model bacterial and archaeal ammonia oxidisers. Environ Microbiol. 2017;19:4882-96.

64. Prosser J, Hink L, Gubry-Rangin C, Nicol GW. Nitrous oxide production by ammonia oxidizers: physiological diversity, niche differentiation and potential mitigation strategies. Glob Chang. Biol. 2020;26:103-18.

65. Lehtovirta-Morley LE, Stoecker K, Vilcinskas A, Prosser Jl, Nicol GW. Cultivation of an obligate acidophilic ammonia oxidizer from a nitrifying acid soil. Proc Natl Acad Sci USA. 2011;108:15892-7.

66. Herbold CW, Lehtovirta-Morley LE, Jung MY, Jehmlich N, Hausmann B, Han P, et al. Ammonia-oxidising archaea living at low pH: Insights from comparative genomics. Environ Microbiol. 2017;19:4939-52.

67. Lehtovirta-Morley LE, Sayavedra-Soto LA, Gallois N, Schouten S, Stein LY, Prosser $\mathrm{Jl}$, et al. Identifying potential mechanisms enabling acidophily in the ammoniaoxidizing archaeon "Candidatus Nitrosotalea devanaterra". Appl Environ Microbiol. 2016;82:2608-19.

68. Jung MY, Kim JG, Sinninghe Damste JS, Rijpstra WI, Madsen EL, Kim SJ, et al. A hydrophobic ammonia-oxidizing archaeon of the Nitrosocosmicus clade isolated from coal tar-contaminated sediment. Environ Microbiol Rep. 2016;8:983-92.

69. Lehtovirta-Morley LE, Ross J, Hink L, Weber EB, Gubry-Rangin C, Thion C, et al. Isolation of 'Candidatus Nitrosocosmicus franklandus', a novel ureolytic soil archaeal ammonia oxidiser with tolerance to high ammonia concentration. FEMS Microbiol Ecol. 2016;92:fiw057.

70. Sauder LA, Albertsen M, Engel K, Schwarz J, Nielsen PH, Wagner M, et al. Cultivation and characterization of Candidatus Nitrosocosmicus exaquare, an ammonia-oxidizing archaeon from a municipal wastewater treatment system. ISME J. 2017;11:1142-57.

71. Nicol GW, Hink L, Gubry-Rangin C, Prosser Jl, Lehtovirta-Morley LE. Genome Sequence of "Candidatus Nitrosocosmicus franklandus" C13, a Terrestrial Ammonia-Oxidizing Archaeon. Microbiol Resour Announc. 2019;8:e00435-19.
72. de la Torre JR, Walker $C B$, Ingalls $A E$, Konneke $M$, Stahl DA. Cultivation of a thermophilic ammonia oxidizing archaeon synthesizing crenarchaeol. Environ Microbiol. 2008;10:810-8.

73. Bower $C E$, Bidwell JP. Ionization of ammonia in seawater: effects of temperature, pH, and salinity. J Fish Res Board Can. 1978;35:1012-6.

74. Bisswanger $\mathrm{H}$. $\mathrm{pH}$ and temperature dependence of enzymes. In: Bisswanger $\mathrm{H}$, editor. Enzyme Kinetics. Weinheim Germany: Wiley-VCH. 2017. p. 145-52.

75. Hamdi S, Moyano F, Sall S, Bernoux M, Chevallier T. Synthesis analysis of the temperature sensitivity of soil respiration from laboratory studies in relation to incubation methods and soil conditions. Soil Biol Biochem. 2013;58: 115-26.

76. Wang C, Morrissey EM, Mau RL, Hayer M, Pineiro J, Mack MC et al. The temperature sensitivity of soil: microbial biodiversity, growth, and carbon mineralization. ISME J. 2021. Online ahead of print.

77. Li PN, Herrmann J, Tolar BB, Poitevin F, Ramdasi R, Bargar JR, et al. Nutrient transport suggests an evolutionary basis for charged archaeal surface layer proteins. ISME J. 2018;12:2389-402.

78. Bale NJ, Palatinszky M, Rijpstra WIC, Herbold CW, Wagner M, Sinninghe Damste JS. Membrane lipid composition of the moderately thermophilic ammoniaoxidizing archaeon "Candidatus Nitrosotenuis uzonensis" at different growth temperatures. Appl Environ Microbiol. 2019;85:e01332-19.

79. Qin W, Carlson LT, Armbrust EV, Devol AH, Moffett JW, Stahl DA, et al. Confounding effects of oxygen and temperature on the TEX86 signature of marine Thaumarchaeota. Proc Natl Acad Sci USA. 2015;112:10979-84.

80. Sorensen TH, Cruys-Bagger N, Windahl MS, Badino SF, Borch K, Westh P. Temperature effects on kinetic parameters and substrate affinity of cel7A cellobiohydrolases. J Biol Chem. 2015;290:22193-202.

81. Szasz G. The effect of temperature on enzyme activity and on the affinity of enzymes to their substrates. Z Klin Chem Klin Biochem. 1974;12:166-70.

82. Frijlink MJ, Abee T, Laanbroek HJ, de Boer W, Konings WN. The bioenergetics of ammonia and hydroxylamine oxidation in Nitrosomonas europaea at acid and alkaline pH. Arch Microbiol. 1992;157:194-9.

83. Taylor AE, Taylor K, Tennigkeit B, Palatinszky M, Stieglmeier M, Myrold DD, et al. Inhibitory effects of C2 to C10 1-alkynes on ammonia oxidation in two Nitrososphaera species. Appl Environ Microbiol. 2015;81:1942-8.

84. Keener WK, Russell SA, Arp DJ. Kinetic characterization of the inactivation of ammonia monooxygenase in Nitrosomonas europaea by alkyne, aniline and cyclopropane derivatives. Biochim Biophys Acta. 1998;1388:373-85.

85. Ward BB. Kinetic studies on ammonia and methane oxidation by Nitrosococcus oceanus. Arch Microbiol. 1987;147:126-33.

86. Schmidt I, Look C, Bock E, Jetten MSM. Ammonium and hydroxylamine uptake and accumulation in Nitrosomonas. Microbiology. 2004;150:1405-12.

87. Tambi H, Flaten GAF, Egge JK, Bødtker G, Jacobsen A, Thingstad TF. Relationship between phosphate affinities and cell size and shape in various bacteria and phytoplankton. Aquat Microb Ecol. 2009;57:311-20.

88. Flynn KJ, Skibinski DOF, Lindemann C. Effects of growth rate, cell size, motion, and elemental stoichiometry on nutrient transport kinetics. PLoS Comput Biol. 2018;14:e1006118.

89. Schut F, Prins RA, Gottschal JC. Oligotrophy and pelagic marine bacteria: facts and fiction. Aquat Micro Ecol. 1997;12:177-202.

90. Harris LK, Theriot JA. Relative rates of surface and volume synthesis set bacterial cell size. Cell. 2016;165:1479-92.

91. Stewart PS. Diffusion in biofilms. J Bacteriol. 2003;185:1485-91.

92. Cesar S, Huang KC. Thinking big: the tunability of bacterial cell size. FEMS Microbiol Rev. 2017:41:672-8.

\section{ACKNOWLEDGEMENTS}

We would like to thank Márton Palatinszky, Ping Han, Michael Lukumbuzya, and Dimitra Sakoula for their assistance with microscopy and culture maintenance. CJS and DK were supported by the Wittgenstein award of the Austrian Science Fund FWF (Z383-B) to MW. PP and CJS were supported by the Austrian Science Fund FWF through the Young Investigators Research Grant program (ZK74). M-YJ was supported by the Research Institute for Basic Sciences (RIBS) of Jeju National University (2019R1A6A10072987) and the National research Facilities and Equipment Center of Korea Basic Science Institute (2020R1A6C101A188) through the National Research Foundation of Korea (NRF) grant funded by the Ministry of Education and MSIT (NRF-2021R1C1C1008303) by the Korea government. S-KR was supported by NRF grant funded by the Ministry of Environment (MOE) of the Republic of Korea (2021R1A2C3004015). CW was supported by a University of East Anglia-funded PhD studentship. LLM was supported by a Royal Society Dorothy Hodgkin Research Fellowship (DH150187) and by a European Research Council (ERC) Starting Grant (UNITY 852993). 


\section{AUTHOR CONTRIBUTIONS}

$M-Y J, C J S, H D$, and MW designed the study and wrote the paper with the help of all authors. M-YJ and CJS performed the kinetic experiments with the help of KDK, $L H$, $\mathrm{BB}, \mathrm{L} \mathrm{L}-\mathrm{M}$, and CW. Additional data analysis was performed by AM, S-KR, PP, GWN, $\mathrm{JRT}$, and $\mathrm{CWH}$.

\section{COMPETING INTERESTS}

The authors declare no competing interests.

\section{ADDITIONAL INFORMATION}

Supplementary information The online version contains supplementary material available at https://doi.org/10.1038/s41396-021-01064-z.

Correspondence and requests for materials should be addressed to M.-Y.J. or C.J.S.

Reprints and permission information is available at http://www.nature.com/ reprints
Publisher's note Springer Nature remains neutral with regard to jurisdictional claims in published maps and institutional affiliations.

(i) Open Access This article is licensed under a Creative Common Attribution 4.0 International License, which permits use, sharing, adaptation, distribution and reproduction in any medium or format, as long as you give appropriate credit to the original author(s) and the source, provide a link to the Creative Commons license, and indicate if changes were made. The images or other third party material in this article are included in the article's Creative Commons license, unless indicated otherwise in a credit line to the material. If material is not included in the article's Creative Commons license and your intended use is not permitted by statutory regulation or exceeds the permitted use, you will need to obtain permission directly from the copyright holder. To view a copy of this license, visit http://creativecommons. org/licenses/by/4.0/.

(c) The Author(s) 2021 